\title{
How to conduct an appraisal of a senior house officer
}

\author{
Michael J Clancy
}

In a typical six month job, appraisal of senior house officers (SHOs) should be undertaken every two months. If there are clear appraisal objectives it is a rewarding exercise, maximising job satisfaction for SHOs and enabling the department to get the best out of them.

The goals of an appraisal are:

(1) Review of performance to date.

(2) Objective setting. The SHO should be encouraged to identify specific training goals which should be agreed by both parties, with plans as to how to achieve them. Ideally it should be possible to measure these goals objectively to confirm progress.

(3) Career development. Often at this stage SHOs will not have fixed career plans but it is usually possible to identify overall career intentions, plus examinations and courses that will help their continuing professional development.

The appraisal is also an opportunity to look at the SHOs potential and how this can be best fulfilled.

For the appraisal to work the following four stages should be undertaken:

\section{(1) Preparation}

It is imperative that both parties are clear about the nature of the appraisal before it is actually undertaken and have the opportunity to add points that they wish to be covered beforehand.

\section{Emergency \\ Department, Southampton General \\ Hospital, Tremona Road, Southampton SO16 6YD}

Correspondence to: Mr Clancy, Consultant.

\section{(2) The appraisal}

The SHO should be given advance notice of when the appraisal is to occur and sufficient uninterrupted time allocated (typically half an hour or so). For the appraisal to work it needs to be fair, open so that each party can speak their minds freely, trusting, and confidential. If this atmosphere is not created the causes of any problems may not emerge. The interview must follow the agreed agenda. The appraiser must be a good listener, avoiding hasty judgments and the temptation to interrupt. If the SHO's performance is good it must be praised and this will provide the best motivation for further improvement. Equally, bad performance must be criticised, but supported by constructive comments on how to improve. During the interview specific training needs will be identified and training plans made. This may involve greater supervision within the department and attending formal courses. Further help may be needed from the postgraduate department, a specialty tutor, or the postgraduate dean. Such help should be sought promptly. Never make promises you can't guarantee. If the postgraduate budget won't allow further training, now is the time to say.

\section{(3) The appraisal report}

This provides a record of the points discussed, past performance, agreed future objectives and plans, training needs, and any matters that remain unresolved. Both parties must have access to the report and agree it.

\section{(4) Follow up}

For appraisal to work there must be some validation of its worth by both sides. Assessment of the success of the appraisal (in terms of numbers of objectives achieved and if not why not) is recommended. An idea of the value of the process can be gained by both sides rating it.

Having subjected your juniors to the process, recognise that senior staff are infrequently appraised and are therefore denied the benefits of such a process. Arrange to be appraised yourself!

An example of the appraisal form used at Bristol Royal Infirmary is shown in fig 1.

\section{Conflict of interest: none.}

Funding: none. 


\section{REVIEW OF TRAINING AT SHO LEVEL}

This form provides a framework for discusssion between Educational Supervisor and $\mathrm{SHO}$ by which the individual educational needs of the SHO can be identified and the appropriate training arranged.

Educational Supervisors are appointed by the Postgraduate Medical Education Department at the BRI. They are responsible for overseeing the educational requirements of their nominated SHO Trainees.

The Postgraduate Medical Educational Department will in turn be jointly responsible to the Medical Postgraduate Dean and the United Bristol Healthcare NHS Trust for the maintenance of educational standards for SHO trainees.

For those SHOs on a 3 month appointment the Educational Supervisor will have an initial review and a final review. For those SHOs on a 6 month (or longer) appointment the Educational Supervisor will have an initial review, a mid point review, and a final review. This form should be kept by the Educational Supervisor and then sent to the Postgraduate Department, Edward Jenner Teaching Centre, Bristol Royal Infirmary after the final review.

No copies should be taken.

\section{SECTION 1 - PERSONAL DETAILS}

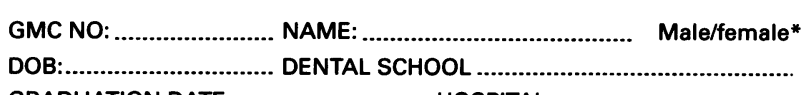

GRADUATION DATE. HOSPITAL:

START DATE (CURRENT POST):

CURRENT POST (SPECIALTY):

PREVIOUS POSTS (including GP):

LOCUM POSTS:

DATES:

(This has been included to identify SHOs who have spent time in locum posts and who might therefore have an unstructured career path.)

\section{SECTION 2 - WHAT ARE YOUR OVERALL CAREER INTENTIONS?}

\section{SECTION 3 - CONTINUING PROFESSIONAL DEVELOPMENT}

What exams/courses/study leave do you need?

EXAMS $\quad$ COURSES

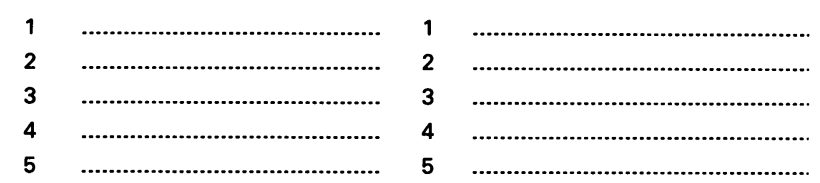

\section{REVIEW OF TRAINING AT SHO LEVEL GUIDELINES}

The following suggestions are to aid Educational Supervisors and SHOs in the process of training review.

The new form is designed to make the review a structured exercise for both Educational Supervisor and SHO. They should compile this together.

\section{SECTION 1}

This section is to elicit demographic information on the trainee and give an outline of the trainee's career to date. It needs to be completed at the initial review. Only data which has been subsequently changed need to be recorded at subsequent reviews.

\section{SECTION 2 - WHAT ARE YOUR OVERALL CAREER INTENTIONS}

This should be a broader statement of the type of career the $\mathrm{SHO}$ is pursuing. It is not necessary for the SHO to have fixed or definate career plans at this stage.

\section{SECTION 3 - CONTINUING PROFESSIONAL DEVELOPMENT}

This identifies exams, courses for which study leave will be requested and which SHOs may need to complete in order to fulfil their career aims.

\section{SECTION 4 - TRAINING IN THIS POST}

This reviews generic and professional/technical skills and the educational plan to be achieved in this post. This section is divided into: first review, mid point review, final review.

\section{SECTION 5 - CHARACTERISTICS OF THE POST}

This section is an attempt to review educational and non-educational variables which provide a measure of the quality of the post. Each variable should be scored on a scale of $1-4$. It should be completed at the final review.

\section{SECTION 6 - EVALUATION}

This is to find out if the appraisal process has been satisfactory to both the Educational Supervisor and the SHO.

\section{FURTHER COMMENTS}

Educational Supervisors and SHOs should add any additional comments at the final review. The contents of this SHO appraisal form are confidential - only impersonal statistical detail will be taken from the computer in the Postgraduate Department. These statistics will be derived only from Sections 1, 3, 5 and 6 and will be depersonalised.

\section{SECTION 4 - TRAINING IN THE POST}

In this section trainees are encouraged to identify specific training goals within the following areas:

\section{FIRST REVIEW}

\section{a) Generic skills}

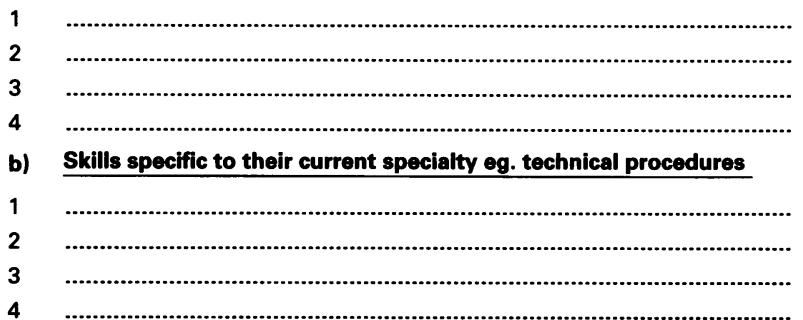

TRAINING PLAN - GOALS

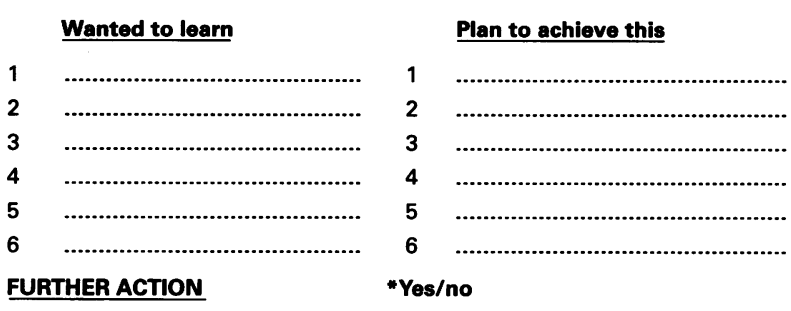

If 'YES' then referred for further advice from $\square$
(1) Consultant
(3) Postgraduate Department
$\square \quad$ (2) Specialty Tutor $\quad \square$
(Tutor/Counsellor)

Figure 1 SHO appraisal form. The form has been reproduced with permission of United Bristol Healthcare NHS Trust who acknowledge it is based on an original idea from the Mersey region. 


\section{MID POINT REVIEW}

\section{Review progress}

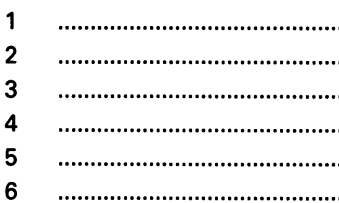

\section{Plan for remaining period of training}

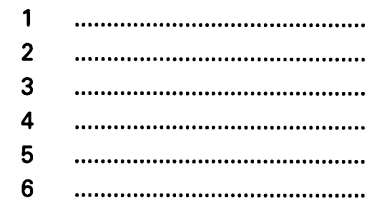

\section{FURTHER ACTION}

\section{*Yes/no}

If 'YES' then referred for further advice from $\square$ :
(1) Consultant
$\square \quad$ (2) Specialty Tutor
(3) Postgraduate Department
(4) Dental Postgraduate Dean

\section{FINAL REVIEW}

\section{Progress achieved}

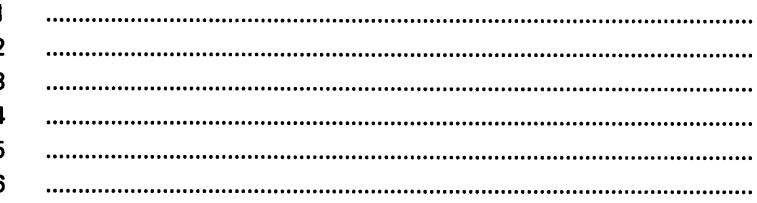

\section{SECTION 5 - EDUCATIONAL CHARACTERISTICS OF THE POST}

\section{FURTHER COMMENTS}

1) SENIOR HOUSE OFFICE

2) EDUCATIONAL SUPERVISOR
(This section to be completed at final review)

Indicate QUALITY of the following scale $\nabla$ :

1: poor, 2: average, 3: good, 4: excellent.

(To be completed by SHO at final review)

\section{EDUCATION}

Availability of protected educational time $1 \square \quad 2 \square \quad 3 \square \quad 4 \square$

Organisation of teaching in post $\quad 1 \square \quad 2 \square \quad 3 \square \quad 4 \square$

Quality of teaching $\quad 1 \square \quad 2 \square \quad 3 \square \quad 4 \square$

Support from Registrars $\quad 1 \square \quad 2 \square \quad 3 \square \quad 4 \square$

Support from Educational Supervisors $\quad 1 \square \quad 2 \square \quad 3 \square \quad 4 \square$

Secretarial support (eg. papers/articles) $1 \square \quad 2 \square \quad 3 \square \quad 4 \square$

Access to library $\quad 1 \square \quad 2 \square \quad 3 \square \quad 4 \square$

Access to medical illustration $\quad 1 \square \quad 2 \square \quad 3 \square \quad 4 \square$

\section{PERSONAL CARE}

Accommodation

Provision of food

(1) Day $\quad 1 \square \quad 2 \square \quad 3 \square \quad 4 \square$

(2) Night $\quad 1 \square \quad 2 \square \quad 3 \square \quad 4 \square$

\section{SECTION 6 - EVALUATION}

$\square$ Usefulness of this appraisal process

1: poor, 2: average, 3: good, 4: excellent

1. Educational Supervisor

$\begin{array}{llll}1 \square & 2 \square & 3 \square & 4 \square\end{array}$

2. $\mathrm{SHO}$

$4 \square$ 